\title{
Rethinking the prototyping process for applying design thinking to business model innovation
}

\author{
AMANO Tsuyoshi $i^{a}$; BRASSETT Jamie ${ }^{a}$ and GREEN Lawrence ${ }^{b}$ and HESTAD Monika ${ }^{c^{*}}$ \\ ${ }^{a}$ Central Saint Martins, United Kingdom \\ b Birmingham City University, United Kingdom \\ cBrand Valley, Norway \\ * Corresponding author: syntropylab@gmail.com \\ doi: 10.33114/adim.2017.148
}

\begin{abstract}
This research proposes a prototyping perspective in design for business model innovation to facilitate disruption. The value of design-led approach for managing innovation has been recognised under the concept of 'design thinking'. In the research on innovation, the concept of business model innovation has been discussed as business models started to be acknowledged as a key aspect of managing innovation. Although experimentation for business model innovation is argued to be of importance, how to apply prototyping of design thinking to business model innovation has been limitedly theorised. This research is based on a literature review to articulate theoretically the concept of prototyping in business model innovation. Through the literature review, this research identifies four key dimensions of prototyping in business model innovation: purpose, process, context and engagement. This paper focuses on the Process dimension to interrogate the existing argument.
\end{abstract}

keywords: design thinking; prototyping; business model innovation; design process

\section{Introduction}

Over the past decade, business model innovation has been acknowledged as an emerging subject and a new approach for innovation management in particular (Chesbrough, 2007; Baden-Fuller et al., 2010; Schneider \& Spieth, 2013) and more broadly for management of organisations as a whole (Pohle \& Chapman, 2006; Chesbrough, 2007; Amit \& Zott, 2010; Teece, 2010). The connection with disruptive innovation with business model innovation is widely acknowledged (e.g., Markides, 2006; Chesbrough, 2010; Koen, 2015) 
Part of the reason why the interest in business model innovation is growing is that the domain of innovation studies itself has extended from a subject focusing on technology policy to an interdisciplinary subject. As the dynamics and complexity surrounding our society are increasing (Wallner, 1999; DG MediaMind Research, 2013; Hausman et al., 2014), organisations come under further pressure of finding a way of managing innovation to survive (Dervitsiotis, 2012). As approaches to tackle the issue, business model innovation and design thinking are emerging subjects in various research fields such as management (e.g., Boland \& Collopy, 2004; Martin, 2009; Lockwood, 2010), innovation studies (e.g., Martin, 2012; Fagerberg et al., 2013) and design methodology research.

As for business models, despite the growing interest, there is still little agreement on what business models are (Teece, 2010; Spieth et al., 2014; Wirtz et al., 2016). Reflecting the diversity of the argument, researchers on business models, Lorenzo Massa and Christopher Tucci (2013) suggest a broad definition of the concept: "the [business model] may be conceptualized as depicting the rationale of how an organization [...] creates, delivers, and captures value [...] in relationship with a network of exchange partners" (p.423; see Afuah \& Tucci, 2003; Osterwalder et al., 2005; Zott et al., 2011).

In the research on business model innovation, some researchers attempt to apply experimental approaches (e.g., Sosna et al., 2010; Hawryszkiewycz, 2014), but there is still little research on prototyping and exploration of new opportunities in designing business models (Osterwalder \& Pigneur, 2013). Furthermore, the approaches are mainly labelled as 'experimentation' (Bucolo \& Wrigley, 2012), and the terms, 'business model experimentation' and 'business model prototyping' are often interchangeably used (e.g., Girotra \& Netessine, 2013), or prototyping is argued without the articulation of the meanings (e.g., Chesbrough, 2010; McGrath, 2010). According to design methodology research, however, the application of the scientific approach to complex problems has been problematic (Rittel, 1972b; Schön, 1983; Buchanan, 1992; Cross, 2011). Thus, developing the theory of business model prototyping will potentially enable researchers and practitioners to understand the process of business model innovation further.

\section{Prototyping in design and design thinking}

The lack of the general definition is pointed out not only about business models but also about design thinking (Liedtka, 2015). Thus, there are several strands in the discussion (Kimbell, 2011; Johansson-Sköldberg et al., 2013), and it is difficult concisely to show the characteristics of design thing. However, former President of the Design Management Institute, Thomas Lockwood, offers a definition of design thinking as "a human centered innovation process that emphasizes observation, collaboration, fast learning, visualization of ideas, rapid concept prototyping, and concurrent business analysis" (2010b, p.xi). This definition encompasses the key features of design thinking that are also argued as applicable to managing the complexity of innovation (e.g., Neumeier, 2008b; Brown, 2009; Martin, 2009).

Although design thinking is a newly argued concept, the complexity of design problems has been argued as 'wicked' problems at least since 1970s in design methodology research (e.g., Rittel, 1972a; Buchanan, 1992). The differences in ways of thinking among science, humanity and design also support the argument that design as a methodology is also distinctive from science's and humanity's methodology as a discipline (Cross, 2001). It is 
argued that design has a different way of thinking for tackling complex problems, and design methodology research turns to develop design as a discipline (Cross, 2007b) or a liberal art (Buchanan, 1992) inherently different from science and humanity. From this perspective, design is not a subject in science or humanity, but a discipline with value for everyone to learn (Archer, 1979; Cross, 1982). The difference influences not only a way of thinking but also the terminology used in design, and the argument of design started to use their own terminology. For instance, in the current argument of design thinking, instead of using a terminology of science such as experimentation, the concept of 'prototyping' is often used to represent a feature of the design methodology for managing the complexity of design problems (e.g., Brown, 2009; Lockwood, 2010b; Liedtka, 2015).

Design thinking can contribute to business model innovation as there are some key points in common, and the commonality suggests that the application of the design methodology can be effective also for business model innovation. Prototyping is regarded as an important aspect in the design methodology and process (e.g., Thomke, 1998; Buchenau \& Suri, 2000; Terwiesch \& Loch, 2004; Hartmann, 2009) as well as a key element of innovation processes in management (Leonard \& Rayport, 1997; Mascitelli, 2000; Schrage, 2000; Thomke, 2008). This section reviews the role of prototyping in design and design thinking.

Sanders (2013) asserts that as fields that design contributes to expand, the role of prototyping also changes. The focus of using prototyping was "to help us see what it could be" (p.63), but in the expanded design fields, the focus also expands "to help us [...] to make sense of the future" (p.64). For this type of prototyping, prototypes are not simply representations of objects but need to be tools for collectively exploring, expressing and testing hypotheses about future ways of living in the world" (p.64).

As prototyping in this thesis is for business model innovation, which is a new area for the design methodology, the argument in this thesis follows the distinction between prototyping and prototypes and the definitions of the concepts above.

Distinctions of prototypes from other concepts are argued in some literature. For instance, interaction design scholar, Lars Erik Holmquist (2005) distinguishes prototypes from mockups and representations. In his theoretical framework, prototypes embody functionality, mock-ups show appearances and representations have both of the attributes. In this thesis, prototypes are not strictly limited as the embodiment of functions for two reasons. One is to avoid turning the terminology to be too complex. The other is that this research rather regards prototypes as "learning tools" (Coughlan et al., 2007, p.124).

As for piloting, in the context of design thinking, the main objective of prototyping is to get feedback and learn from building and implementing a product or service (Brown, 2008; Lockwood, 2010). This point is sometimes argued as a distinctive difference between prototyping and piloting, which aims at evaluating the feasibility of the product or service (NESTA, 2011).

Therefore, as long as mock-ups and representations are used for learning, they are perceived as 'prototypes' in this research. Further detail will be argued in the following subsections. 


\section{A theoretical framework of business model prototyping}

This section reviews five conceptual frameworks of prototyping in existing literature to enable this research to theoretically argue about prototyping (McCurdy et al., 2006; Beaudouin-Lafon \& Mackay, 2007; Lim et al., 2008; Blomkvist \& Holmlid, 2011; Jensen et al., 2015). As various frameworks coexist, there are also various ways to selecting and synthesising the key dimensions of prototyping. However, the main objective of making a conceptual framework in this section is not to precisely represent what prototyping is but to provide a conceptual foundation for the argument of business model prototyping. Thus, the selection and synthesis of the key dimensions are based on the assumption that prototyping is applicable to something intangible and complex problems as various arguments on design thinking do (e.g., Brown, 2009; Lockwood, 2010b; Jobst \& Meinel, 2014; Almahmoud et al., 2016). This focus influences the choice of terminology and priorities for each dimension, and also pays more attention to simplicity than precision of the framework. The selected literature spans from Human Computer Interaction, Engineering design, Interactive design and service design (see Table 1).

Human-computer interaction $(\mathrm{HCl})$ researchers, McCurdy et al. (2006) assert that measuring prototypes only by whether they are low fidelity or high fidelity is too simple, and propose five dimensions of prototypes: the level of visual refinement, the breadth of functionality, the depth of functionality, the richness of interactivity and the richness of data models. As their main concern is interaction between computer and the users, the dimensions are set up for how prototypes can be interactive.

Also, in the argument of prototyping in interactive systems, computer scientists, Michel Beaudouin-Lafon and Wendy Mackay (2007) propose a set of key elements of prototyping for interactive design (p.1018):

- representation - the type of the prototype and how it is represented

- precision - how much detail is represented in the prototype

- interactivity - the degree of the capacity for users to interact with the prototype

- evolution - the role of the prototype in the whole expected life cycle

While Beaudouin-Lafon and Mackey see $\mathrm{HCl}$ as an interdisciplinary subject among science, engineering, and design, they claim that "prototyping is primarily a design activity" (2007, p.1018).

Other researchers in $\mathrm{HCl}$, Youn-Kyung Lim, Erik Stolterman and Josh Tenenberg (2008) propose a theoretical framework of prototyping consisting of dimensions of 'filters' and 'manifestations of idea' as parts of prototyping. Filtering dimensions are the focus of design ideas that designers choose to prototype, and manifestation dimensions are how to represent the ideas. In the framework, both filters and manifestations have subattributes. The former's sub-attributes are:

- Appearance

- Data

- Functionality

- Interactivity

- Spatial structure 
The latter's three sub attributes are defined as (p. 11):

- Material - Medium (either visible or invisible) used to form a prototype

- Resolution - Level of detail or sophistication of what is manifested (corresponding to fidelity)

- Scope - Range of what is covered to be manifested

In this framework, what to prototype and how to prototype are considered as two key metrics of arguing types of prototyping.

From a service design perspective, Blomkvist and Homlid (2011) formulate a framework of service prototyping based on expert interviews and literature review. Dimensions in the framework contain purpose, position in process, author, audience, validity, technique, fidelity and representation. While the frameworks from $\mathrm{HCl}$ and interactive design tend to focus on how prototypes are developed, this framework pays more attention to the context surrounding prototyping processes.

More recently, engineering design academics, Matilde Jensen, Stephanie Balters and Martin Steinert (2015) reviewed the literature of theoretical prototyping frameworks to formulate a general model of prototyping. Through a statistic analysis of the literature, they identify important themes of prototyping: material, interactivity, visual detail, purpose, surroundings and technology. Although the authors aim to contribute to engineering design, their review includes Blomkvist and Homlid's work above and the framework also acknowledges the importance of context in prototyping.

Through the review and comparison of the frameworks, this research develops a theoretical framework of prototyping consisting of key four dimensions: purpose, process, context and engagement.

'Purpose' is what prototyping is done for, 'process' is how prototyping is conducted. 'Context' is in what circumstance prototyping is carried out and 'engagement' is how prototyping encourages the participants to engage. Context includes participants, environment and culture as the sub-dimensions. Although 'engagement' is usually argued as representation, interactivity or fidelity of prototypes, the selection of those attributes depends on how to make the participants engage with prototypes and prototyping processes. Thus, this research uses the term, engagement as a dimension relevant to representation, interactivity and fidelity of prototypes. 
Table 1 Prototyping dimensions

\begin{tabular}{|c|c|c|c|c|c|}
\hline Authors & $\begin{array}{l}\text { McCurdy et al. } \\
(2006)\end{array}$ & $\begin{array}{l}\text { Lim et al. } \\
(2008)\end{array}$ & $\begin{array}{l}\text { Jensen et al. } \\
(2015)\end{array}$ & $\begin{array}{l}\text { Beaudouin- } \\
\text { Lafon and } \\
\text { Mackay (2007) }\end{array}$ & $\begin{array}{l}\text { Blomkvist and } \\
\text { Holmlid (2011) }\end{array}$ \\
\hline Discipline & $\begin{array}{l}\text { Human-Computer } \\
\text { Interaction }\end{array}$ & $\begin{array}{l}\text { Human- } \\
\text { Computer } \\
\text { Interaction }\end{array}$ & $\begin{array}{l}\text { Engineering } \\
\text { Design }\end{array}$ & $\begin{array}{l}\text { Interactive } \\
\text { Design }\end{array}$ & Service Design \\
\hline $\begin{array}{l}\text { List of } \\
\text { dimensions }\end{array}$ & $\begin{array}{l}\text { - The level of } \\
\text { visual } \\
\text { refinement } \\
\text { - The breadth } \\
\text { of } \\
\text { functionality } \\
\text { - The depth of } \\
\text { functionality } \\
\text { - The richness } \\
\text { of } \\
\text { interactivity } \\
\text { - The richness } \\
\text { of data } \\
\text { model }\end{array}$ & $\begin{array}{l}\text { Filtering } \\
\text { - Appearance } \\
\text { - Data } \\
\text { - Functionality } \\
\text { - Interactivity } \\
\text { - Spatial } \\
\text { structure } \\
\text { Manifestation } \\
\text { - Material } \\
\text { - Resolution } \\
\text { - Scope }\end{array}$ & $\begin{array}{l}\text { - Material } \\
\text { - Interacti } \\
\text { vity } \\
\text { - Visual } \\
\text { detail } \\
\text { - Purpose } \\
\text { - Surroun } \\
\text { dings } \\
\text { - Technol } \\
\text { ogy }\end{array}$ & $\begin{array}{l}\text { - Representation } \\
\text { - Precision } \\
\text { - Interactivity } \\
\text { - Evolution }\end{array}$ & $\begin{array}{l}\text { - Purpose } \\
\text { - Position in } \\
\text { the entire } \\
\text { Process } \\
\text { - Author } \\
\text { - Audience } \\
\text { - Validity } \\
\text { - Technique } \\
\text { - Fidelity } \\
\text { - Representa } \\
\text { tion }\end{array}$ \\
\hline
\end{tabular}

\section{The process of business model prototyping}

This chapter argues the process of business model prototyping as a key dimension. As we will see, the process of prototyping, as well as the design process, is argued in various ways. While normative process models of both design and business model innovation suggest that prototyping is located in a late stage of the process, the importance of conducting prototyping as early as possible is also acknowledged.

This section discusses the position of prototyping in a design process. Initially, it clarifies a normative model of the design process and business model innovation through literature as a theoretical foundation for identifying where prototyping is located in the processes. These models suggest that prototyping is in the late stage of the process. However, it is also assert that prototyping should be done as soon as possible. The following sections reviews the arguments with the consideration of the relationships with purposes and fidelity.

\section{Prototyping in a late stage}

By integrating seminal frameworks of the process of design thinking (IDEO, Continuum, Stanford Design School, Rotman Business School, Darden Business School), Liedtka (2015) proposes three sequential stages in the design process: exploring stage, idea generation stage and testing stage. Prototyping is included in the testing stage. She also mentions the similarity of the steps to the key methods of design thinking proposed by Seidel \& Fixton (2013): need finding, brainstorming and prototyping. Glen et al. (2015) argue the applicability of design thinking to the curriculum of business schools, and propose brief steps of design thinking. In their steps, prototyping and testing is the fifth step in six steps. These models commonly locate prototyping in a late stage of the process (see Table 2). 
In some frameworks of prototyping for business model innovation, the idea generation phase is set before the prototyping phase. For example, Seidenstricker et al. (2014) suggest a systematic idea generation and selection phases for business model prototyping should be conducted before prototypes are actually developed. This point is in line with the process models of design thinking (see Liedtka, 2015).

Table 2 Process models of design thinking (adopted from Liedtka (2015) and modified by the author)

\begin{tabular}{|c|c|c|c|c|c|c|c|}
\hline 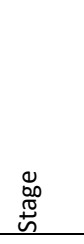 & 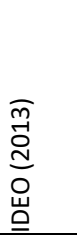 & 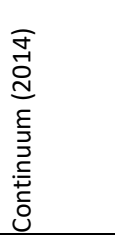 & 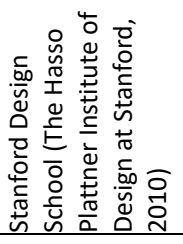 & 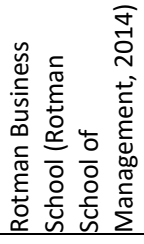 & 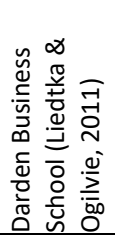 & 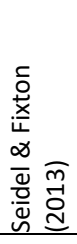 & 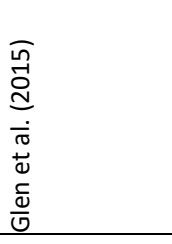 \\
\hline 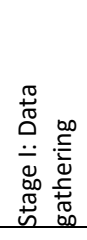 & 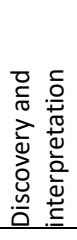 & 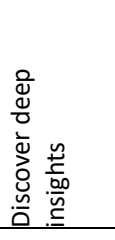 & 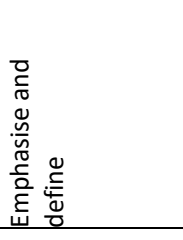 & 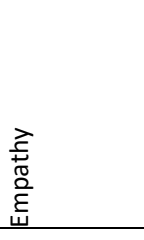 & 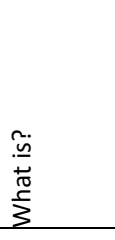 & 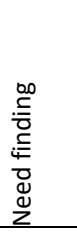 & 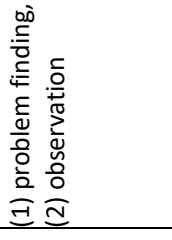 \\
\hline 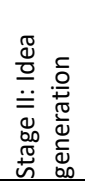 & 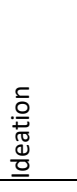 & 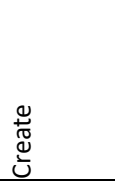 & 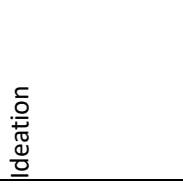 & 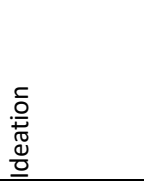 & 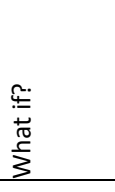 & 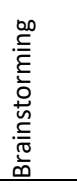 & 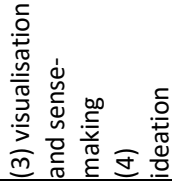 \\
\hline 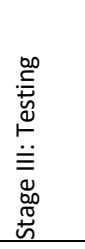 & 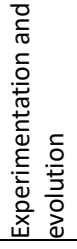 & 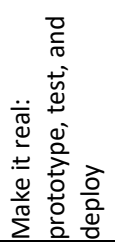 & 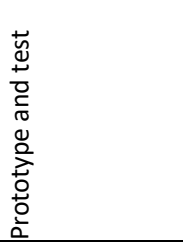 & 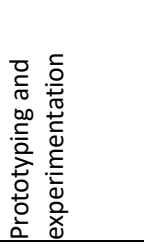 & 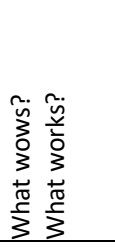 & 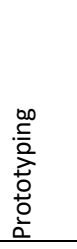 & 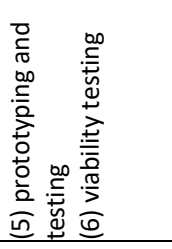 \\
\hline
\end{tabular}

Researchers of business model innovation struggles with finding a process model of business model innovation in management. Thus, they borrow the structure from design (e.g., Zott \& Amit, 2015). Although the importance of business model innovation has been recognised, there exists little academic research on the process of business model design, let alone business model innovation (Bucherer et al., 2012; Zott \& Amit, 2015). Due to difficulty in finding normative process models for business model innovation from literature in management, Zott and Amit (2015) explore process models in the design literature (e.g., Beckman \& Barry, 2007; Bhavani \& Sosa, 2008; Brown, 2008) and propose a five step process model for business model innovation: observe, synthesise, generate, refine and implement. Following a notion of Owen (1993), they assert that the first two steps are in the analytical stage, and the last three steps are in the synthetic stage.

From the study of entrepreneurship, Osterwalder and Pigneur (2010) also propose a five step model of business model design: mobilise, understand, design, implement and manage. One of the characteristics of this model is that it starts from mobilise, which other models do not often include. Combining the five steps by Osterwalder and Pigneur 
with knowledge from their own experience, Bucherer et al. (2012) offer a similar process model: analysis, design, implementation and control. In the study of product development, Frankenberger et al. (2013) propose four phases of business model innovation based on innovation management literature and their case studies: initiation, ideation, integration and implementation. The first three phases are for designing business models, and the last one is for realising it.

By synthesising the models in literature, this research theorises the process of business model innovation with the stages of mobilise, understand, innovate, develop and implement (see Table 3). As it suggests, prototyping is located in a late stage of the process, the implement phase in particular, also in the process models of business model innovation.

Table 3 Process models of business model innovation

\begin{tabular}{|c|c|c|c|c|c|c|c|}
\hline Author & Discipline & Moblise & $\begin{array}{l}\text { Understa } \\
\text { nd }\end{array}$ & Ideate & Develop & & Implement \\
\hline 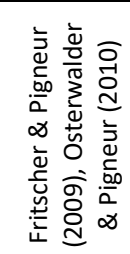 & 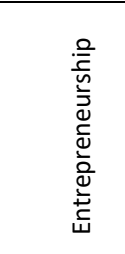 & 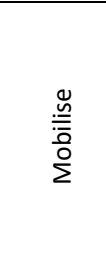 & Understand & Design & 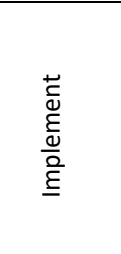 & $\begin{array}{l}\text { Manage } \\
\text { (refinem } \\
\text { ent) }\end{array}$ & \\
\hline 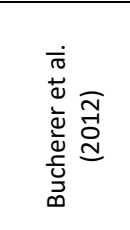 & 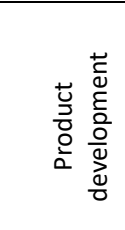 & & Analysis & \multicolumn{3}{|c|}{ Design (an iterative process) } & 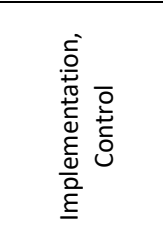 \\
\hline \multirow{2}{*}{ 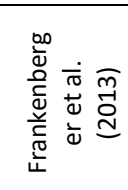 } & \multirow{2}{*}{ 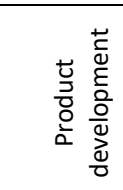 } & & Design & & & & Realisation \\
\hline & & & Initiation & Ideation & \multicolumn{2}{|c|}{ Integration } & $\begin{array}{l}\text { Implementati } \\
\text { on }\end{array}$ \\
\hline \multirow[b]{2}{*}{ 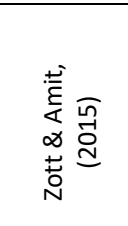 } & \multirow[b]{2}{*}{ 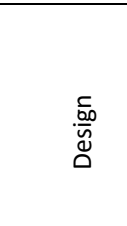 } & & Analytic & Synthetic & & & \\
\hline & & & Observe & 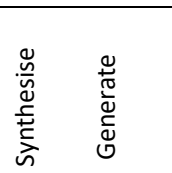 & Refine & & Implement \\
\hline
\end{tabular}

\section{Prototyping in an early stage}

Although the process models of design and business model innovation shown in the previous subsection locate prototyping in a late stage, it is also claimed that prototyping in design thinking should be conducted in an early stage (Jobst \& Meinel, 2014). In engineering design, Yang claims a "prototype is an early embodiment of a design concept" (2005, p.650). Also, in the argument of social service development, NESTA (2011) defines "Prototyping is an approach to developing and testing ideas at an early stage before large- 
scale resources are committed to implementation" (p. 6). It is believed that benefits of prototyping in an early stage are saving costs and time of product and service development (Houde \& Hill, 1997; McCurdy et al., 2006; Coughlan et al., 2007). These arguments suggest that while prototyping is located in a late stage of design process in normative frameworks of design and business model innovation processes, some literature recognises the importance of embodying ideas in 'an early stage' of the process. Although how early it should be does not clear in most of the arguments, the claims conflict with most of the normative models leaving prototyping to a late stage of a design process.

To understand the conflict between the two notions, the relationship of the design process with the purpose of prototyping should be considered. It is argued that the position of prototyping in the design process is connected with the purpose of prototyping (Voss \& Zomerdijk, 2007; Blomkvist \& Holmlid, 2011; Sanders, 2013). From this perspective, prototyping for exploration tends to be located in an early stage of the design process. As prototyping for evaluation needs to have more specified ideas, it needs to be located in a later stage than exploration (Blomkvist \& Holmlid, 2011). Also, prototyping for persuasion is generally located later than evaluation (Voss \& Zomerdijk, 2007; Blomkvist \& Holmlid, 2011) or at the end of the process (Sanders, 2013).

\section{Process and fidelity of prototyping}

Another pattern of the process models of design is that high-fidelity prototypes are used in a late stage, while low-fidelity prototypes are used in early stages. For instance, based on the argument of Skogstad (2009), Vetterli et al. (2012) propose four milestones of prototyping processes following the requirements of prototypes: Critical Function Prototype, Dark Horse Prototype, Functional Prototype and Final Prototype. In this model, prototyping moves from conceptual prototypes to more concrete prototypes. Similarly, Ullman (2009) proposes four classes of prototypes based on the difference of the purposes: proof-of-concept prototypes, proof-of-product prototypes, proof-of-process prototypes and proof-of-production prototypes. In this process model, prototypes in later stages need to prove a more specific issues by higher-fidelity prototypes. Both models indicate the increase of fidelity during the iterative prototyping process. Also, it is argued that "the level of precision usually increases as successive prototypes are developed and more and more details are set" (Beaudouin-Lafon \& Mackay, 2007, p.1019). Referring to Sommerville ([1995] 2010), Yang (2005) suggests that there are three stages of prototyping in software engineering: throwaway, evolutionary and incremental. In this process, prototypes in an early stage should be designed to be thrown away, and changes in a late stage are supposed not to be radical but only incremental.

In these process models, the purpose and the stage of prototypes are connected through fidelity of prototypes, and the categorisation of prototypes is based on the level of embodiment of ideas. The process models are based on the assumption that ideas represented in prototypes are gradually verified through iteration. This assumption could be controversial when design problems are seen as wicked problems, as the concept of wicked problems assert that verifying the viability of solutions through trials and errors is questionable because of the complexity in the context surrounding problems (see Rittel \& 
Webber, 1973). Also, the process model with increasing fidelity does not well explain radical changes of the direction in new business (see Ries, 2011; Blank \& Dorf, 2012).

The relationship between the purpose and position of prototyping can be also seen in the argument on the relationship between prototyping and piloting. In the context of social service development, NESTA (2011) describes the difference between prototyping and piloting based on the purpose and the position in the design process. Prototyping is in an earlier phase than piloting and the main purpose is to develop services. On the other hand, piloting is located in a later stage of the design process than prototyping for exploration, and the purpose is the refinement of well-verified services essentially for rolling out and scaling the service. Additionally, service designer working with NESTA, Aviv Katz (2011) asserts that the difference between prototyping and piloting as, "there are two main types of prototyping: exploratory (done in early stages of insight and idea generation) and developmental (done after the service has been specified and you know what you're designing). The former is quick and cheap; the latter requires more planning". Here, also, the purpose and position of prototyping are interconnected, and even fidelity of prototyping is influenced by the factors. From this point of view, prototyping can be both in an early stage and also a late stage, but the purpose of prototyping needs to shift from exploration to evaluation to persuasion.

\section{Agility in prototyping}

While design processes based on phases are identified as we have seen above, learning through iterative processes is frequently mentioned as a characteristics of prototyping (e.g., Hartmann et al., 2006; Brown, 2008; Leifer \& Meinel, 2011). This iterative aspect is also characterised as 'agility' (e.g., Neumeier, 2008b; Mootee, 2013). Agility is a widely used concept as a key element of design thinking for managing uncertainty in facilitating disruptive types of innovation (e.g., Brown, 2008; Neumeier, 2008a; Lockwood, 2010b). Agility is also recognised as an effective element for managing innovation as well as business processes, as it is in effect to manage uncertainty surrounding innovation (e.g., Thomke \& Reinertsen, 1998; Bessant et al., 2005). In terms of uncertainty in managing innovation, Christensen (2003) claims that a new market cannot be analysed even by market experts. To tackle the uncertainty, designers build a product or service to learn, not to complete it. Production processes should be flawless, but when you regard production processes as part of learning activities, even failure can be used as a learning opportunity (see Rodriguez \& Jacoby, 2007).

Despite the growing awareness on the importance of agility, the meaning of agility in design is not clearly articulated (see Lindberg et al., 2011). Iterative processes are in common with other practices dealing with uncertainty such as agile development in IT development and the Lean Startup methodology in entrepreneurship. Indeed, it is asserted that the concept of agility was originally formulated in the study of software development (Abbas et al., 2008). Larman and Basili (2003) also claim that, through the historical review of iterative and incremental development (IID), using iteration for managing uncertainty is not a new approach for software development. Moreover, not only in IT development and design, there is a methodology of developing business models to a viable business through iteration called 'Lean Startup' methodology in entrepreneurship (Blank, 2005; Ries, 2011; Blank \& Dorf, 2012; Maurya, 2012). The 
methodology encourages entrepreneurs to expect business development is not a linear but iterative process (Ries, 2011).

In the Lean Startup methodology, there are two key concepts, pivot and Minimum Viable Product (MVP), that characterise the methodology. Similar to prototyping in design, the lean startup methodology usually goes through an iterative process. The methodology relies on a launch of a product that is minimally developed to gain feedback from the market, which is conceptualised Minimum Viable Product. After each iteration, the user of the approach needs to interpret the feedback from the market and decide whether to keep improving the current product (persevere) or change the direction of the business (pivot). Pivot is defined as "structured course correction designed to test a new fundamental hypothesis about the product, strategy, and engine of growth" (Ries, 2011, p.149).

Despite the similarity to other approaches for tackling uncertainty, researchers of design thinking, Tilmann Lindberg, Christoph Meinel and Ralf Wagner (2011) argue that, although a core feature of design thinking is described as "iterative learning and development processes" (p.11), agility in design thinking is different from agile development in IT development at some points. First, agile development tends to reduce options, but the iterative process in design thinking is for diversifying ideas. Secondly, agile development in IT development is less collaborative than that in design thinking. From this understanding, iteration in the design approach is not only for mitigating risks but exploring potential opportunities and supporting collaboration with and involvement of stakeholders. When prototyping is regarded as an exploration, iteration or agility is not only for incremental improvement but can be a source of discontinuous changes.

\section{Prototyping as philosophy and culture}

The previous subsections show the discussions to locate prototyping in a certain phase of a design process. In addition, prototyping is also discussed as a culture and philosophy of design approaches as well as the agile aspect of design. Rather, this research faces difficulty in clearly identifying in which phase prototyping should be. In this regard, this research supports the arguments asserting prototyping as a culture and philosophy of design, and the notion can be applied for business model innovation. From business model's point view, final solutions can be a prototype in a long term. Also, prototyping is identified as the core of implementation in social innovation (Brown \& Wyatt, 2010). In this process, business models can be seen as fundamental tools for supporting the development of a new business. Therefore, the difference between the development and implementation phases rather derive from the level of exposure of porotypes to external stakeholders such as customers and clients. Feedback gained from the exposure can be a key source of learning for developing business models. Thus, implementation can be seen part of business model development. This point is rather close to the concept of 'effectuation', which is an attitude of learning through doing rather than planning (Sarasvathy, 2001).

Moreover, for business model prototyping, prototyping for evaluation or persuasion can provide also learning opportunities for exploration due to the complexity of business model development. Thus, it is difficult to identify where the position of business model prototyping should be in the entire process of business model development in advance. 
Rather, learning opportunities seem to exist at any point of business model development processes.

Although this argument undermines the value of normative process models, such models are useful for convincing stakeholders unfamiliar with the process. For the purpose, the process of design and business model innovation is simplified to clarify the benefits of applying a design approach to complex problems by people outside of the design discipline. This simplification and formalisation, however, also causes confusion of the position of prototyping in the process. Thus, articulating the position of prototyping in the design process as a phase-based model may not be suitable to represent the dynamics in the process.

By contrast to the arguments supporting formal models, some researchers point out that prototyping is part of the philosophy and culture of design (Kauber, 1985; Schrage, 1993; Schrage, 1996; Thomke \& Nimgade, 2000; Pering, 2002; Brown, 2005), which also suggests that prototyping is part of the design process from the beginning to the end. This resonates with the space model of the design thinking process proposed by Brown (2008). The space model suggests the interconnections among inspiration, ideation and implementation phases. In this model, prototyping can be conducted throughout the design process.

Overall, while various process models indicate that prototyping is an activity in a late stage of the whole process, some theories suggest that prototyping can be effective in an early stage if the position of prototyping is correctly aligned with the purpose of prototyping and the fidelity of prototypes. Furthermore, prototyping can work as a philosophy and culture of the design process. The process of business model prototyping can be also considered as not only iterative but also overlapped over the entire design process. This understanding of prototyping in design is in line with the notion that design is an agile approach (e.g., Neumeier, 2008; Lindberg et al., 2011; Leifer \& Meinel, 2011; Mootee, 2013). While agility is argued as a characteristic of processes, it is also considered as an organisational property or "competence" (e.g., Neumeier, 2008a). When prototyping is regarded as philosophy or culture of design, agility can be regarded as part of the philosophy or culture. Although agility is characterised with the iterative process, it does not explain well about the discontinuity in the prototyping process. The following sections will argue it with the concept of evolution and emergence.

\section{Discontinuity in the process}

While iteration is an important characteristic of the innovation process, it is reported by practitioners that most of new businesses go through a major change of direction during the iterative business development process (e.g., Blank, 2005; Ries, 2011). Likewise, it is also asserted that while iteration is useful for incremental innovation, 'windows of opportunity' to change get narrowed in quick iterations unless there are interruptions such as unexpected events or new discoveries (Tyre \& Orlikowski, 1994). This point suggests that an iterative approach is effective to manage uncertainty, but at the same time how to manage discontinuity in the process has to be considered to successfully exploit the value of the prototyping process as exploration. In practice, difficulty is in making a decision in the conflict between improving the current solution and exploring new possibilities. It is asserted that "there is a tension between evolving toward the final 
solution and exploring an unexpected design direction, which may be adopted or thrown away completely" (Beaudouin-Lafon \& Mackay, 2007, p.1020).

Regarding design problems as complex problems, each iteration in the prototyping process should include the reconfiguration of prototypes as the business situation dynamically changes and each iteration affects the next iteration (Rittel \& Webber, 1973). In other words, each iteration is not the same as it affects the mindset and knowledge of project members is accumulated through the iteration. Thus, the analogy of tornado or a representation of the process in a spring shape is more suitable than a horizontallyrecurred circle. Similarly, Lim et al. (2008) assert that the process of prototyping is organic and evolutional.

Although the differences among iteration, increment and evolution are not often argued, software developer, Allan Kelly (2011) divides agile development into three types, which are iterative, incremental and evolutionary development. Iterative development turns large requirements to be small sized requirements that can be managed by short term iterations. In iterative development, predetermined tasks and goals are assumed to be well defined and correct. Thus, even though it uses an iterative approach, all the effort is made for a big product launch and changing requirements is perceived negatively. Incremental development is similar to and based on incremental development, but the product release cycle is shorter than iterative development to gain users' feedback. Therefore, changes are a positive move and reducing tasks is regarded as saving, although it still starts with predetermined requirements. By contrast, evolutionary development starts with a loose set of requirements, as the approach is based on the assumption that it is hardly possible to identify all the requirements in advance. Not only in software development, specifying required features before prototyping is also questioned in product development (e.g., Boehm et al., 1984; Rudd et al., 1996; Thomke \& Bell, 2001).

The process is goal-oriented, and through the process, new requirements and opportunities are emerged and identified. The development has to be measured by how much progress is achieved towards the goal rather than by how many pre-set tasks are done. An important point for this paper is that evolutionary development is a parallel process of creating solutions and discovering new requirements and opportunities.

From this perspective, the findings of this research suggest the term, evolution should be intentionally chosen to describe the process of business model prototyping. It is also argued that business models are a subject to evolve rather than something staying in the same state (Chesbrough \& Rosenbloom, 2002; Mitchell \& Coles, 2003; Gerasymenko et al., 2015). Thus, at least in the context of business model prototyping, the process can be seen as an evolutionary process as the development of prototypes works as an exploratory process for new opportunities.

Following the argument of the evolutionary process, another question is raised; how the emergence of new requirements and opportunities occurs. Some arguments suggest that iterations gradually improve a solution. For instance, Fixton and Rao (2014) claim that "emergent strategy is an iterative process, one experiment leads to another, and to another, in each case closing in on a workable solution" (p.49). As they apparently regard the iterations as experiments, this might not be exactly the case of prototyping, but an issue in emergent processes is that it is uncertain about whether the direction is right or 
wrong, and the accumulation of knowledge through iteration is more likely to lead to a fairly radical change of direction (Tyre \& Orlikowski, 1994; Ries, 2011; Bogers \& Horst, 2014).

Emergence requires deep understanding of the context of innovation opportunities. Peschl and Fundeider (2015, p.142) introduce the concept of emergent innovation, and suggest that the realisation of potential opportunities requires an exploration for a profound understanding on the key contexts. The aim of business model prototyping can be to gain this level of understanding of a new business, and it is expected to lead the emergence of innovation through new business models.

The advantage of the iteration may be to generate the dynamics in the power structure for decision making to widen a window of opportunity to change (see Tyre \& Orlikowski, 1994). In other words, iteration is not for gradually validating the parts of business models, but deconstructing and rebuilding the organisational situation for identifying new opportunities for business model innovation. In addition, as the importance of principles and cultures is asserted, simply following the process may not result in intended outcomes.

\section{Conclusion}

This paper reviews the arguments about process models of prototyping for managing innovation. While some normative process models are developed in the existing literature, this research identifies the nature of prototyping as a philosophy or culture embedded in the entire innovation process. As there is difficulty in finding the existing literature about the process model of business model innovation (Zott \& Amit, 2015), this research contribute to the literature by providing a prototyping perspective to the discussion on business model innovation. This research mainly relies on literature, and further research based on empirical data will strengthen the prototyping perspective for managing business model innovation.

\section{References}

Abbas, N., Gravell, A.M. \& Wills, G.B. (2008) Historical Roots of Agile Methods: Where Did 'Agile Thinking' Come From? In: P. Abrahamsson, R. Baskerville, K. Conboy, B. Fitzgerald, L. Morgan, \& $X$. Wang eds. Agile Processes in Software Engineering and Extreme Programming. Lecture Notes in Business Information Processing. Springer Berlin Heidelberg, pp.94-103. Available from: $<$ http://link.springer.com/chapter/10.1007/978-3-540-68255-4_10> [Accessed 26 October 2015].

Afuah, A. \& Tucci, C.L. (2003). Internet Business Models and Strategies: Text and Cases. 2nd edition. New York, McGraw-Hill.

Almahmoud, J., Almalki, A., Alrashed, T. \& Alwabil, A. (2016) Prototyping Complex Systems: A Diary Study Approach to Understand the Design Process. In: A. Marcus ed. Design, User Experience, and Usability: Design Thinking and Methods. Lecture Notes in Computer Science. Springer International Publishing, pp.187-196.

Amit, R. \& Zott, C. (2010). Business model innovation: Creating value in times of change. IESE Business School.

Archer, B. (1979) Design as a discipline. Design Studies, 1(1), 17-20.

Baden-Fuller, C., Demil, B., Lecoq, X. \& MacMillan, I. (Mac) eds. (2010). Business Models [Special Issue]. Long Range Planning, 43(2-3). 
Beaudouin-Lafon, M. \& Mackay, W.E. (2007) Prototyping Tools and Techniques. In: A. Sears \& J. A. Jacko eds. The Human-Computer Interaction Handbook: Fundamentals, Evolving Technologies and Emerging Applications. New York, CRC Press, pp.1017-1039.

Beckman, S.L. \& Barry, M. (2007) Innovation as a learning process: Embedding design thinking. California Management Review, 50(1), 25.

Berger, E.S.C. \& Kuckertz, A. eds. (2016) Complexity in Entrepreneurship, Innovation and Technology Research: Applications of Emergent and Neglected Methods. 1st ed. 2016 edition. Springer.

Bessant, J., Lamming, R., Noke, H. \& Phillips, W. (2005). Managing innovation beyond the steady state. Technovation, 25(12), 366-1376.

Bhavani, R. \& Sosa, M. (2008) IDEO: Service Design (A). INSEAD.

Blank, S.G. (2005) The four steps to the epiphany. Cafepress. com.

Blank, S.G. \& Dorf, B. (2012). The startup owner's manual: the step-by-step guide for building a great company. K\&S Ranch, Incorporated.

Blomkvist, J. \& Holmlid, S. (2011) Existing Prototyping Perspectives: Considerations for Service Design. In: Nordes. Helsinki, Finland, pp.1-10. Available from:

<http://www.nordes.org/opj/index.php/n13/article/view/101> [Accessed 6 January 2016].

Boehm, B.W., Gray, T.E. \& Seewaldt, T. (1984) Prototyping versus specifying: a multiproject experiment. IEEE transactions on Software Engineering, (3), 290-303.

Bogers, M. \& Horst, W. (2014) Collaborative Prototyping: Cross-Fertilization of Knowledge in Prototype-Driven Problem Solving. Journal of Product Innovation Management, 31(4), 744-764.

Boland, J., Richard J. \& Collopy, F. eds. (2004). Managing as designing. Stanford University Press.

Brown, T. (2009). Change by design: how design thinking transforms organizations and inspires innovation. New York: HarperCollins Publishers.

Brown, T. (2008). Design thinking. Harvard Business Review, 86(6), 84-92.

Brown, T. (2005) Strategy by Design. Fast Company. Available from: <http://www.fastcompany.com/52795/strategy-design> [Accessed 29 June 2016].

Brown, T. \& Wyatt, J. (2010). Design thinking for social innovation. Development Outreach, 12(1), 29-43.

Buchanan, R. (1992). Wicked problems in design thinking. Design Issues, 8(2), 5-21.

Buchenau, M. \& Suri, J.F. (2000). Experience prototyping. In: Proceedings of the 3rd conference on Designing interactive systems: processes, practices, methods, and techniques. pp.424-433.

Bucherer, E., Eisert, U. \& Gassmann, O. (2012) Towards Systematic Business Model Innovation: Lessons from Product Innovation Management. Creativity and Innovation Management, 21(2), 183-198.

Bucolo, S. \& Wrigley, C. (2012) Using a design led approach to emotional business modelling. In: Leading Innovation through Design: Proceedings of the DMI 2012 International Research Conference. Boston, MA, USA, pp.323-333.

Chesbrough, H. (2007) Business model innovation: it's not just about technology anymore. Strategy \& Leadership, 35(6), 12-17.

Chesbrough, H. (2010) Business model innovation: opportunities and barriers. Long Range Planning, 43(2), 354-363.

Chesbrough, H. \& Rosenbloom, R.S. (2002) The role of the business model in capturing value from innovation: evidence from Xerox Corporation's technology spin-off companies. Industrial and Corporate Change, 11(3), 529-555.

Christensen, C.M. (2003) The Innovator's Dilemma: The Revolutionary Book That Will Change the Way You Do Business. Reprint. Harper Paperbacks. 
Coughlan, P., Suri, J.F. \& Canales, K. (2007) Prototypes as (Design) Tools for Behavioral and Organizational Change: A Design-Based Approach to Help Organizations Change Work Behaviors. The Journal of Applied Behavioral Science, 43(1), 122-134.

Cross, N. (2011). Design thinking: Understanding how designers think and work. Berg.

Cross, N. (1982). Designerly ways of knowing. Design studies, 3(4), 221-227.

Cross, N. (2001). Designerly ways of knowing: design discipline versus design science. Design Issues, 17(3), 49-55.

Cross, N. (2007a). Forty years of design research. Design Studies, 28(1), 1-4.

Cross, N. (2007b). From a design science to a design discipline: Understanding designerly ways of knowing and thinking. In: R. Michel ed. Design Research Now. Basel, Switzerland, Birkhäuser $\mathrm{GmbH}, \mathrm{pp} .41-54$.

Dervitsiotis, K.N. (2012). An innovation-based approach for coping with increasing complexity in the global economy. Total Quality Management \& Business Excellence, 23 (9-10), pp.997-1011.

DG MediaMind Research (2013). The Complexity Index. DG MediaMind Research. Available from: <http://www2.mediamind.com/Data/Uploads/ResourceLibrary/The_Complexity_Index.pdf> [Accessed 16 August 2016].

Fagerberg, J., Martin, B.R. \& Andersen, E.S. (2013). Innovation Studies: Towards a New Agenda. In: J. Fagerberg, B. R. Martin, \& E. S. Andersen eds. Innovation Studies: Evolution and Future Challenges. Oxford University Press, pp.1-17.

Fixson, S.K. \& Rao, J. (2014). Learning Emergent Strategies Through Design Thinking. Design Management Review, 25(1), 46-53.

Frankenberger, K., Weiblen, T., Csik, M. \& Gassmann, O. (2013). The 4I-framework of business model innovation: A structured view on process phases and challenges. International Journal of Product Development, 18(3-4), 249-273.

Gerasymenko, V., De Clercq, D. \& Sapienza, H.J. (2015) Changing the Business Model: Effects of Venture Capital Firms and Outside CEOs on Portfolio Company Performance. Strategic Entrepreneurship Journal, 9(1), 79-98.

Girotra, K. \& Netessine, S. (2013) OM Forum - Business Model Innovation for Sustainability. Manufacturing \& Service Operations Management, 15(4), 537-544.

Glen, R., Suciu, C., Baughn, C.C. \& Anson, R. (2015). Teaching design thinking in business schools. The International Journal of Management Education, 13(2), 182-192.

Hartmann, B. (2009) Gaining design insight through interaction prototyping tools. Stanford University.

Hartmann, B., Klemmer, S.R., Bernstein, M., Abdulla, L., Burr, B., Robinson-Mosher, A. \& Gee, J. (2006) Reflective physical prototyping through integrated design, test, and analysis. In:

Proceedings of the 19th annual ACM symposium on User interface software and technology. UIST '06. New York, NY, USA, ACM, pp.299-308. Available from: $<$ http://dl.acm.org/citation.cfm?id=1166300> [Accessed 20 April 2014].

Hausman, R., Hidalgo, C.A., Bustos, S., Coscia, M., Simoes, A. \& Yıldırım, M.A. (2014). The Atlas of Economic Complexity: Mapping Paths to Prosperity. The updated edition. Cambridge, MA, The MIT Press.

Hawryszkiewycz, I. (2014). Creating Design Spaces for Business Model Innovation. In: AMCIS 2014 Proceedings.

Holmquist, L.E. (2005). Prototyping: Generating Ideas or Cargo Cult Designs? Interactions, 12(2), 4854.

Houde, S. \& Hill, C. (1997) What do prototypes prototype? In: Handbook of human-computer interaction. pp. 367-381.

Jensen, M.B., Balters, S. \& Steinert, M. (2015) Measuring Prototypes: A Standardized Quantitative Description of Prototypes and Their Outcome for Data Collection and Analysis. In: DS 80-2 
Proceedings of the 20th International Conference on Engineering Design (ICED 15) Vol 2: Design Theory and Research Methodology Design Processes. Milan, Italy.

Jobst, B. \& Meinel, C. (2014) How Prototyping Helps to Solve Wicked Problems. In: L. Leifer, H. Plattner, \& C. Meinel eds. Design Thinking Research. Understanding Innovation. Springer International Publishing, pp.105-113.

Johansson-Sköldberg, U., Woodilla, J. \& Çetinkaya, M. (2013) Design thinking: past, present and possible futures. Creativity and Innovation Management, 22(2), 121-146.

Katz, A. (2011). Top tips and insights for public service prototyping [Internet]. Available from: <http://iu.dev.ecobee.org/blog/201105/top-tips-and-insights-public-service-prototyping> [Accessed 12 June 2011].

Kauber, P.G. (1985). Prototyping: Not a method but a philosophy. Journal of Systems Management, 36(9), 28-33.

Kelly, A. (2011). The Agile Spectrum. Overload Journal, 102.

Kimbell, L. (2011) Rethinking Design Thinking: Part I. Design and Culture, 3(3), 285-306.

Koen, P. (2015). Lean Startup in Large Enterprises Using Human-Centered Design Thinking: A New Approach for Developing Transformational and Disruptive Innovations. Rochester, NY, Social Science Research Network.

Larman, C. \& Basili, V.R. (2003). Iterative and incremental development: A brief history. Computer, 36(6), 47-56.

Leifer, L. \& Meinel, C. (2011). Design Thinking Research. In: H. Plattner, C. Meinel, \& L. Leifer eds. Design Thinking: Understand - Improve - Apply. Springer, pp.xiii-xxi.

Leonard, D. \& Rayport, J.F. (1997). Spark Innovation Through Empathic Design. Harvard Business Review, 75(6), 102-113.

Liedtka, J. (2015) Perspective: Linking Design Thinking with Innovation Outcomes through Cognitive Bias Reduction. Journal of Product Innovation Management, 32(6), 925-938.

Lim, Y.-K., Stolterman, E. \& Tenenberg, J. (2008). The anatomy of prototypes: Prototypes as filters, prototypes as manifestations of design ideas. ACM Transactions on Computer-Human Interaction (TOCHI), 15 (2, Article 7), pp.1-27.

Lindberg, T., Meinel, C. \& Wagner, R. (2011). Design Thinking: A Fruitful Concept for IT Development? In: C. Meinel, L. Leifer, \& H. Plattner eds. Design Thinking. Understanding Innovation. Springer Berlin Heidelberg, pp.3-18. Available from:

<http://link.springer.com/chapter/10.1007/978-3-642-13757-0_1> [Accessed 12 February 2016].

Lockwood, T. ed. (2010a) Design thinking: integrating innovation, customer experience and brand value. New York NY, Allworth Press.

Lockwood, T. (2010b) Forward: The Importance of Integrated Thinking. In: T. Lockwood ed. Design thinking: integrating innovation, customer experience and brand value. New York NY, Allworth Press, pp.vii-xvii.

Markides, C. (2006) Disruptive Innovation: In Need of Better Theory. Journal of product innovation management, 23(1), 19-25.

Martin, B.R. (2012). The evolution of science policy and innovation studies. Research Policy, 41(7), 1219-1239.

Martin, R. (2009). The design of business: why design thinking is the next competitive advantage. Harvard Business Press, Boston, Mass.

Mascitelli, R. (2000). From Experience: Harnessing Tacit Knowledge to Achieve Breakthrough Innovation. Journal of Product Innovation Management, 17(3), 179-193.

Massa, L. \& Tucci, C.L. (2013). Business model innovation. In: The Oxford Handbook of Innovation Management. Oxford University Press, pp.420-441.

Maurya, A. (2012). Running Lean: Iterate from Plan A to a Plan That Works. O'Reilly Media. 
McCurdy, M., Connors, C., Pyrzak, G., Kanefsky, B. \& Vera, A. (2006). Breaking the Fidelity Barrier: An Examination of Our Current Characterization of Prototypes and an Example of a Mixed-fidelity Success. In: Proceedings of the SIGCHI Conference on Human Factors in Computing Systems. CHI '06. New York, NY, USA, ACM, pp.1233-1242.

McGrath, R.G. (2010). Business models: A discovery driven approach. Long range planning, 43(2), 247-261.

Mitchell, D. \& Coles, C. (2003). The ultimate competitive advantage of continuing business model innovation. Journal of Business Strategy, 24(5), 15-21.

Moggridge, B. (2007). Designing interactions. MIT press Cambridge.

Mootee, I. (2013). Design Thinking for Strategic Innovation: What They Can't Teach You at Business or Design School. 1 edition. Hoboken, N.J, John Wiley \& Sons.

NESTA (2011) Prototyping in Public Services. Available from: <http://www.nesta.org.uk/sites/default/files/prototyping_public_services.pdf>.

Neumeier, M. (2008a). The designful company. Design Management Review, 19(2), pp.10-15.

Neumeier, M. (2008b). The Designful Company: How to Build a Culture of Nonstop Innovation. 1st ed. Peachpit Press.

Osterwalder, A. \& Pigneur, Y. (2010). Business Model Generation: A Handbook for Visionaries, Game Changers, and Challengers. Wiley.

Osterwalder, A. \& Pigneur, Y. (2013). Designing Business Models and Similar Strategic Objects: The Contribution of IS. Journal of the Association for Information Systems, 14(5), 237-244.

Osterwalder, A., Pigneur, Y. \& Tucci, C.L. (2005). Clarifying business models: Origins, present, and future of the concept. Communications of the association for Information Systems, 16(1), 1-25.

Owen, C. (1993). Considering design fundamentally. Design Processes Newsletter, 5(3), 2.

Pering, C. (2002). Interaction Design Prototyping of Communicator Devices: Towards Meeting the Hardware-software Challenge. Interactions, 9(6), 36-46.

Peschl, M.F. \& Fundneider, T. (2015). Emergent Innovation as a driver for changing organizational design. In: Wissen verändert. p.141. Available from:

<http://www.researchgate.net/profile/Benedikt_Lutz/publication/273130078_Wissen_verndert. _Beitrge_zu_den_Kremser_Wissensmanagement-

Tagen_2014/links/54f866740cf2ccffe9df150a.pdf\#page=145> [Accessed 26 October 2015].

Pohle, G. \& Chapman, M. (2006). IBM's global CEO report 2006: business model innovation matters. Strategy \& Leadership, 34(5), 34-40.

Ries, E. (2011). The lean startup: How today's entrepreneurs use continuous innovation to create radically successful businesses. Crown Business.

Rittel, H.W. (1972a). On the Planning Crisis: Systems Analysis of 'the First and Second Generations'. Bedriftsøkonomen, 8, 390-396.

Rittel, H.W. (1972b). Son of Rittelthink: The State of the Art in Design Methods. The Design Methods Group.

Rittel, H.W. \& Webber, M.M. (1973). Dilemmas in a general theory of planning. Policy sciences, 4(2), 155-169.

Rodriguez, D. \& Jacoby, R. (2007). Embracing Risk to Learn, Grow and Innovate.

Rudd, J., Stern, K. \& Isensee, S. (1996). Low vs. high-fidelity prototyping debate. Interactions, 3(1), 76-85.

Sanders, E.B.-N. (2013). Prototyping for the Design Spaces of the Future. In: L. Valentine ed. Prototype: Design and Craft in the 21st Century. London, Bloomsbury Academic, pp.59-74.

Sarasvathy, S.D. (2001) Causation and effectuation: Toward a theoretical shift from economic inevitability to entrepreneurial contingency. Academy of management Review, 26 (2), pp.243263. 
Schneider, S. \& Spieth, P. (2013). Business model innovation: Towards an integrated future research agenda. International Journal of Innovation Management, 17(1), 15-35.

Schön, D.A. (1983). The reflective practitioner. Basic Books New York.

Schrage, M. (1996). Cultures of Prototyping. In: T. Winograd ed. Bringing Design to Software. New York, NY, USA, ACM, pp.191-213.

Schrage, M. (2000). Serious play: How the world's best companies simulate to innovate. Harvard Business Press.

Schrage, M. (1993). The culture (s) of prototyping. Design Management Journal (Former Series), 4(1), 55-65.

Seidel, V.P. \& Fixson, S.K. (2013). Adopting Design Thinking in Novice Multidisciplinary Teams: The Application and Limits of Design Methods and Reflexive Practices. Journal of Product Innovation Management, 30, pp.19-33.

Seidenstricker, S., Scheuerle, S. \& Linder, C. (2014). Business Model Prototyping-Using the Morphological Analysis to Develop New Business Models. Procedia-Social and Behavioral Sciences, 148, pp.102-109.

Skogstad, P.L.S. (2009). A unified innovation process model for engineering designers and managers. Stanford University. Available from: <http://gradworks.umi.com/33/64/3364513.html> [Accessed 20 October 2015].

Sommerville, I. (2010). Software Engineering. 9 edition. Boston, Pearson.

Sosna, M., Trevinyo-Rodríguez, R.N. \& Velamuri, S.R. (2010). Business Model Innovation through Trial-and-Error Learning: The Naturhouse Case. Long Range Planning, 43(2-3), 383-407.

Spieth, P., Schneckenberg, D. \& Ricart, J.E. (2014). Business model innovation - state of the art and future challenges for the field. $R \& D$ Management, 44(3), 237-247.

Teece, D.J. (2010). Business models, business strategy and innovation. Long range planning, 43(2), 172-194.

Terwiesch, C. \& Loch, C.H. (2004). Collaborative prototyping and the pricing of custom-designed products. Management Science, 50(2), 145-158.

Thomke, S. (2008). Learning by experimentation: Prototyping and testing. In: C. H. Loch \& S. Kavadias eds. Handbook of New Product Development Management. Oxford, ButterworthHeinemann, pp.401-420.

Thomke, S. \& Bell, D.E. (2001). Sequential testing in product development. Management Science, 47(2), 308-323.

Thomke, S. \& Reinertsen, D. (1998). Agile product development: managing development flexibility in uncertain environments. California management review, 41(1), 8-30.

Thomke, S.H. (1998). Managing Experimentation in the Design of New Products. Management Science, 44(6), 743-762.

Thomke, S.H. \& Nimgade, A. (2000). IDEO Product Development. Harvard Business School. Available from: <http://www.hbs.edu/faculty/Pages/item.aspx?num=27285> [Accessed 3 August 2016].

Tsai, W.-C. (2014) Application of Complexity Science Perspective on New Business Development: A Case Study of VISA Organization. Journal of International Management Studies, 9(2), 152.

Tyre, M.J. \& Orlikowski, W.J. (1994). Windows of opportunity: Temporal patterns of technological adaptation in organizations. Organization science, 5(1), 98-118.

Ullman, D.G. (2009). The Mechanical Design Process. 4th edition. Boston, McGraw-Hill Higher Education.

Vetterli, C., Hoffmann, F., Brenner, W., Eppler, M.J. \& Uebernickel, F. (2012). Designing innovation: Prototypes and team performance in design thinking. In: Proceedings of the 23rd International Society of Professional Innovation Management Conference - Action for Innovation: Innovating from Experience. Barcelona. Available from: 
$<$ https://www.alexandria.unisg.ch/export/DL/Walter_Brenner/223840.pdf> [Accessed 29 June 2015].

Voss, C. \& Zomerdijk, L. (2007). Innovation in Experiential Services - An Empirical View. In: The Department of Trade and Industry (DTI) ed. Innovation in Services. Occasional Paper. London, DTI, pp.97-134.

Wallner, H.P. (1999). Towards sustainable development of industry: networking, complexity and eco-clusters. Journal of Cleaner Production, 7(1), 49-58.

Wirtz, B.W., Pistoia, A., Ullrich, S. \& Göttel, V. (2016). Business Models: Origin, Development and Future Research Perspectives. Long Range Planning, 49(1), 36-54.

Yang, M.C. (2005) A study of prototypes, design activity, and design outcome. Design Studies, 26(6), 649-669.

Zott, C. \& Amit, R. (2015). Business Model Innovation: Toward a Process Perspective. In: C. E. Shalley, M. A. Hitt, \& J. Zhou eds. The Oxford Handbook of Creativity, Innovation, and Entrepreneurship. Oxford; New York, OUP USA.

Zott, C., Amit, R. \& Massa, L. (2011). The business model: Recent developments and future research. Journal of management, 37(4), 1019-1042.

About the Authors

Tsuyoshi Amano has been interested in how to apply design thinking to business model innovation through prototyping. He contributed to DMI Conference 2014 and Business Model Conference in 2017.

Dr Jamie Brassett is Reader in Philosophy, Design and Innovation at Central Saint Martins, and Subject Leader and MA Course Director of Innovation Management.

Dr Lawrence Green is Director of Research: Art \& Design at Birmingham City University. He worked at Oxford University, Manchester University, Manchester Metropolitan University and Central St Martins. Much of his research activity focuses on innovation and design-related issues.

Dr Monika Hestad is founder of the strategic consultancy Brand Valley and an associate lecturer at Central Saint Martins. She holds a PhD in industrial design and brand building. Her research interest is design thinking, branding and innovation. 